HEALTH PSYCHOLOGY REPORT · VOLUME 9(2), 2021 ORIGINAL ARTICLE
Inger Schou-Bredal $\mathbb{D}$

$1,2 \cdot \mathrm{A}, \mathrm{B}, \mathrm{C}, \mathrm{D}, \mathrm{E}, \mathrm{F}$

Tine Grimholt (D)

$3,4 \cdot A, B, D, E, F$

Tore Bonsaksen (D)

$5,6 \cdot A, B, C, D, E$
Laila Skogstad $\mathbb{D}$ $7,8 \cdot A, B, C, D, E$

Trond Heir (D)

$9,10 \cdot \mathrm{A}, \mathrm{B}, \mathrm{C}, \mathrm{D}, \mathrm{E}$

Øivind Ekeberg (D)

$11 \cdot A, B, C, D, E$

\title{
Optimists' and pessimists' self-reported mental and global health during the COVID-19 pandemic in Norway
}

\begin{abstract}
BACKGROUND
The COVID-19 pandemic represents a global health crisis. How well people cope with this situation depends on many factors, including one's personality, such as dispositional optimism. The aim of the study was to investigate: 1) optimists' and pessimists' concerns during lockdown, and mental and global health; 2) whether pessimists without known risk factors more often than optimists report being at risk for COVID-19.
\end{abstract}

\section{PARTICIPANTS AND PROCEDURE}

A snowball sampling strategy was used; 4,527 people, 18 years or older, participated in a survey on a variety of mental health conditions and COVID-19 worries. In addition, they completed the Life Orientation Test-Revised (LOT-R). Optimism was defined by LOT-R $f \geq 17$.

\section{RESULTS}

Fewer optimists than pessimists reported that they were worried about COVID-19, respectively $51.2 \%$ vs. $66.8 \%$, $p<.001$. Among those reporting none of the known so- matic risk factors, more pessimists than optimists ( $14.3 \%$ vs. $9.1 \%, p<.001)$ considered themselves at risk of a fatal outcome from COVID-19. Significantly fewer optimists reported that they had anxiety (5.1\%), depression (3.4\%), suicidal ideation $(0.7 \%)$ and insomnia $(19.3 \%)$ during the COVID-19 outbreak than pessimists ( $24.7 \%$ anxiety, $18.4 \%$ depression, $5.4 \%$ suicidal ideation, $39.8 \%$ insomnia, all $p<.001)$. Optimists reported better global health than pessimists $(87.2$ vs. $84.6, p<.001)$.

\section{CONCLUSIONS}

Optimists were generally less worried about the COVID-19 pandemic than pessimists and reported better mental and global health during lockdown. Pessimists more often than optimists reported being at risk for COVID-19 without reporting known risk factors.

KEY WORDS

anxiety; COVID-19; depression; dispositional optimism; insomnia

ORGANIZATION - 1: Faculty of Medicine, University of Oslo, Oslo, Norway · 2: Department of Cancer, Oslo University Hospital, Oslo, Norway · 3: Department of Acute Medicine, Oslo University Hospital, Oslo, Norway · 4: Faculty of Health Studies, VID Specialized University, Oslo, Norway · 5: Department of Health and Nursing Science, Faculty of Social and Health Sciences, Inland Norway University of Applied Sciences, Elverum, Norway · 6: Faculty of Health Studies, VID Specialized University, Sandnes, Norway · 7: Faculty of Health Sciences, Oslo Metropolitan University, Oslo, Norway · 8: Department of Research, Sunnaas Rehabilitation Hospital HF, Nesodden, Norway · 9: Norwegian Center for Violence and Traumatic Stress Studies, Oslo, Norway · 10: Institute of Clinical Medicine, University of Oslo, Oslo, Norway · 11: Department of Mental Health and Addiction, Oslo University Hospital, Oslo, Norway

AUthors' CONTRibutions - A: Study design - B: Data collection · C: Statistical analysis - D: Data interpretation . E: Manuscript preparation · F: Literature search · G: Funds collection

CORRESPONDing AUthor - Inger Schou-Bredal, Ph.D., University of Oslo / Oslo University Hospital, Boks 1072 Blindern, Postboks 4950 Nydalen 0316, 0424 Oslo, Norway, e-mail: i.s.bredal@medisin.uio.no 


\section{BACKGROUND}

The World Health Organization declared the coronavirus disease 2019 (COVID-19) outbreak in January 2020 to be a public health emergency of international concern (Mahase, 2020). On March 12, 2020, Norway took measures to curb the spread of the COVID-19 pandemic, said to be the most far-reaching measures Norway's population has ever experienced in peacetime. On that day, the country introduced a ban on public events and activities, and closed kindergartens, schools, and educational institutions. Citizens were told to avoid public transportation, journeys, and contact with other people. Those who had been exposed to COVID-19 or who had entered the country from outside the Nordic countries were asked to self-quarantine for 14 days. Those who had a confirmed COVID-19 infection were isolated. Older citizens and those at risk due to other illness were recommended to self-quarantine. On March 16, Norway shut its ports and airports to stop the virus from spreading.

Changes in life can be stressful and may lead to anxiety, fear of disease contagion, tenseness, irritability, restlessness, emotional distress, and concentration difficulties (Cava et al., 2005). How well people cope with this new alien situation will vary and depends on many factors, for example, one's personality. The personality trait of optimism is considered a psychological resource, and is widely supported by research indicating associations with improved well-being and physical health (Carver \& Scheier, 2014; Schou-Bredal et al., 2017). One reason may be that optimists experience less distress than pessimists in adverse conditions (Colby \& Shifren, 2013; Hirsch et al., 2012; Schou et al., 2004).

It has been shown that optimism remains stable over situations as well as over time and regardless of negative effects (Schou et al., 2005; Schou-Bredal \& Ekeberg, 2016). When optimists and pessimists are exposed to a pandemic, they may react differently. If so, this may demonstrate a diversity of human responses to a pandemic.

The aim of this study was to investigate the following questions.

1. To what degree are optimists and pessimists concerned about the COVID-19 pandemic?

2. Do pessimists report more often than optimists being at risk of experiencing COVID-19 complications without having any known risk factors?

3. Do pessimists report more mental health problems (anxiety, depression, insomnia, and suicidal ideation), worse global health, or more alcohol use during lockdown than optimists?

\section{PARTICIPANTS AND PROCEDURE}

\section{STUDY DESIGN}

A population-based cross-sectional survey (the CORONAPOP survey) was conducted from April 8 to May 20,
2020, using an anonymous online questionnaire. The data collection adopted purposive and snowball sampling strategies. The web link was hosted and disseminated by several institutions, including Oslo University Hospital, the University of Oslo, Oslo Metropolitan University, and Sunnaas Rehabilitation Hospital. The link to the survey was further disseminated on social media platforms such as Facebook, Twitter, LinkedIn, and Instagram by the individual researchers and other individuals who wanted to share the link to the survey. All data were collected as self-report measures via the web-based survey.

\section{PARTICIPANTS}

The study population consisted of adult Norwegian citizens (aged 18 years or older) who responded to the web link. Since the study was also featured in national and local newspapers with online links, participants came from several regions of Norway. There were no exclusion criteria.

\section{MEASUREMENTS}

Several questionnaires on COVID-19 had already been published online. However, none of these covered the specific issues related to COVID-19 that we wanted to examine. Therefore, we developed a questionnaire to assess these problems. Our item selection was guided by topics that were addressed in the Norwegian Population Study health survey, which was conducted as a postal survey in 2014-2015 (Schou-Bredal et al., 2017). In addition, the CORONAPOP survey included topics addressed in the news media about worries that citizens might experience because of COVID-19.

Sociodemographic data collected were: age group (18-29 years, 30-39 years, 40-49 years, 50-59 years, 60-69 years, $\geq 70$ years), sex, highest completed education level (elementary school, high school, less than four years of higher education, and four years of higher education or more), employment status now (working/ in education vs not), during the COVID-19 outbreak, living with spouse or partner vs not), and size of place of residence $(<200$ inhabitants, 200-19,999 inhabitants, 20,000-99,999 inhabitants, $\geq 100,000$ inhabitants).

Mental health-related data. The questionnaire included the question: "Below is a list of health problems: Do you have, or have you had, any of these?". Among the listed problems were anxiety, depression, insomnia, suicide ideation, and suicide attempts. The answer options were: "no", "yes", and "last month" (i.e., during the COVID-19 lockdown). Those who confirmed having anxiety, depression, or insomnia during the last month were classified as currently having a relevant mental health problem. They were also asked if they used alcohol. Response options were: "no", "sometimes", "weekly", "daily", and "several times daily". For
Optimists' and pessimists' mental health during the COVID-19 pandemic 
alcohol, we distinguished between daily use vs less frequent/no use. In addition, respondents were asked if they currently had any of the following diseases: heart disease, hypertension, lung disease, cancer, diabetes, cardiovascular insult, or other diseases/illness that were viewed as a risk. The answer options here were "yes" or "no".

Problems related to the pandemic. Relating to the COVID-19 situation, participants were asked to respond "yes" or "no" to the following questions: a) "Have you been infected with COVID-19?"; b) "Have you been in quarantine or in isolation due to the coronavirus?"; c) "Are you at risk of experiencing complications from COVID-19?"; d) "Do you have financial concerns?"; e) "Are you suffering, or do you think you will suffer, economic loss?"; and f) "Are you generally worried about the pandemic?"

All respondents who had answered "yes" to the question "Are you at risk of experiencing complications from COVID-19?" were defined to be in the subjective risk group, whereas the objective risk group included all those who had reported to have one or more of the following diseases: heart disease, hypertension, diabetes, cancer, lung disease, or other diseases that put them at risk; or were $\geq 70$ years of age.

Self-rated global health was assessed with a measure based on two items from the European Organization for Research and Treatment of Cancer Quality of Life Questionnaire (EORTC QLQ-C30; Aaronson et al., 1993). The items were: "How has your health been during the last week?" and "How has your quality of life been during the last week?" The response format for both questions was an 11-point scale ranging from 0 (very poor) to 10 (excellent). The global health measure is established by calculating the average score for the two items and then transforming this score to represent a point on a 0-100 scale (i.e., multiply the raw score by 10 ).

The Life Orientation Test-Revised (LOT-R) was used to measure dispositional optimism (Scheier et al., 1994). The LOT-R is a 10 -item self-report measure; four of the items are filler items that are included to disguise (somewhat) the underlying purpose of the test. Of the six scored items, three are phrased in an optimistic and three in a pessimistic direction. The respondents indicated the extent to which they agreed with each of the items on a 5-point scale from 0 (strongly disagree) to 4 (strongly agree). The time frame was the present. Scores range from 0 to 24; higher scores indicate greater optimism, and lower scores indicate greater pessimism (Scheier et al., 1994). The LOT-R has been translated into Norwegian using the multiple forward and backward translation technique recommended by Guillemin et al. (1993), and has been used previously in Norwegian populations (Schou-Bredal et al., 2017; Schou et al., 2004). In an earlier validation study, the internal con- sistency was $\alpha=.78$ (Scheier et al., 1994); in the present study, the value was $\alpha=.74$. The term pessimist in this study refers to LOT-R scores $<17$ and optimist to LOT-R scores $\geq 17$ (Schou-Bredal et al., 2017).

\section{DATA ANALYSIS}

IBM SPSS Statistics (ver. 24) was used for statistical analyses. Descriptive demographic and self-reported health data are presented with frequencies and percentages. The chi-square test was used to assess whether the frequency of health conditions and worries differed significantly between optimists and pessimists. The independent $t$ test was used to compare optimists' and pessimists' global health and the results are presented with means and $95 \%$ confidence interval (CI) to indicate the precision of mean values. Pearson's correlations were conducted to examine the bivariate relationship between variables. The significance level was $5 \%$.

\section{ETHICS}

Ethical approval permission to conduct the study was given (REK no. 130447). The questionnaires were answered anonymously.

\section{RESULTS}

A total of 4,527 respondents answered the questionnaire, of whom $1,766(39.0 \%)$ were classified as optimists ( $\geq 17$ score on LOT-R) and $2,761(61.0 \%)$ as pessimists $(<17$ score on LOT-R). The mean LOT-R score for optimists was 19.3 (95\% CI $[19.2,19.4])$ and for pessimists it was 11.9 (95\% CI [11.8, 12.0]). Sociodemographic data are presented in Table 1 . There was no significant difference between optimists and pessimists regarding having been infected with COVID-19 (1.7\% vs. $1.3 \% ; \chi^{2}(2, N=4,527)=1.93$, $p=.250)$, or having been in quarantine/isolation $\left(26.7 \%\right.$ vs. $\left.29.2 \% ; \chi^{2}(2, N=4,527)=3.26, p=.073\right)$.

1. To what degree are optimists and pessimists concerned about the COVID-19 pandemic?

Compared with pessimists, significantly fewer optimists had financial concerns during the COVID-19 outbreak $\left(27.2 \%\right.$ vs. $13.2 \% ; \chi^{2}(2, N=4,527)=124.77$, $p<.001)$ and fewer optimists reported that they suffered, or thought they would suffer, economic loss $\left(20.8 \%\right.$ vs. $\left.28.5 \% ; \chi^{2}(2, N=4,527)=40.30, p<.001\right)$. Compared with pessimists, fewer optimists reported that they were generally worried about the pandemic $\left(51.2 \%\right.$ vs. $\left.66.8 \% ; \chi^{2}(2, N=4,527)=109.22, p<.001\right)$.

2. Do pessimists report more often than optimists being at risk of experiencing COVID-19 complications without having any known risk factors? 
Table 1

Sociodemographic (\%)

\begin{tabular}{|c|c|c|c|c|}
\hline & $\begin{array}{c}\text { Optimists } \\
n=1,766 \\
\end{array}$ & $\begin{array}{c}\text { Pessimists } \\
n=2,761 \\
\end{array}$ & $p$ & \multirow{14}{*}{$\begin{array}{l}\text { Optimists' } \\
\text { and pessimists' } \\
\text { mental health } \\
\text { during the } \\
\text { COVID-19 } \\
\text { pandemic }\end{array}$} \\
\hline Gender $(\%)$ & & & .001 & \\
\hline Female & 82.4 & 86.7 & & \\
\hline Male & 17.4 & 12.7 & & \\
\hline Age groups $(\%)$ & & & .001 & \\
\hline $18-19$ & 1.2 & 1.8 & & \\
\hline $20-29$ & 16.6 & 28.6 & & \\
\hline $30-39$ & 24.3 & 28.6 & & \\
\hline $40-49$ & 24.9 & 17.8 & & \\
\hline $50-59$ & 20.4 & 14.7 & & \\
\hline $60-69$ & 10.0 & 6.4 & & \\
\hline $70-79$ & 2.0 & 1.7 & & \\
\hline $80-89$ & 0.3 & 0.4 & & \\
\hline$>90$ & 0.1 & & & \\
\hline Place of residence $(\%)$ & & & .934 & \\
\hline Rural (<200 inhabitants) & 3.9 & 4.3 & & \\
\hline Village (200-19,999 inhabitants) & 25.1 & 25.2 & & \\
\hline Town (20,000-99,999 inhabitants) & 24.7 & 23.7 & & \\
\hline City ( $\geq 100,000$ inhabitants) & 46.0 & 46.5 & & \\
\hline Education level > 12 years $(\%)$ & 83.0 & 70.7 & .001 & \\
\hline \multicolumn{5}{|l|}{ Employed or in education (\%) } \\
\hline Before COVID-19 pandemic & 90.4 & 86.2 & .001 & \\
\hline During COVID-19 pandemic & 84.9 & 78.5 & .001 & \\
\hline Civil status (\%) & & & .001 & \\
\hline Married & 67.1 & 55.5 & & \\
\hline Boy/girlfriend & 5.8 & 7.8 & & \\
\hline Widow & 1.1 & 1.1 & & \\
\hline Divorced & 4.6 & 3.8 & & \\
\hline Single & 21.4 & 31.9 & & \\
\hline \multicolumn{5}{|l|}{ Living situation (\%) } \\
\hline Living alone & 17.3 & 24.9 & .001 & \\
\hline With parents & 5.5 & 8.0 & .001 & \\
\hline Spouse & 66.9 & 55.5 & .001 & \\
\hline Person $>18$ years & 17.1 & 15.5 & .159 & \\
\hline Children $<18$ years & 38.4 & 31.4 & .001 & \\
\hline
\end{tabular}


Inger

Schou-Bredal, Tine Grimholt, Tore Bonsaksen, Laila Skogstad, Trond Heir, Øivind Ekeberg
Among optimists, $19.4 \%(n=343)$ reported that they considered themselves to be at risk of experiencing complications from COVID-19 (the subjective risk group), whereas $20.7 \%$ belonged to the objective risk group. Among pessimists $26.0 \%(n=718)$ were in the subjective risk group and $20.9 \%(n=579)$ in the objective risk group (Table 2). Significantly more pessimists than optimists $(14.3 \%$ vs. 9.1\%; $\left.\chi^{2}(1, n=3,790)=23.71, p<.001\right)$ reported that they were at risk of experiencing complications from COVID-19, without having reported that they had any of the known risk factors.

3. Do pessimists report more mental health problems (anxiety, depression, insomnia, and suicidal ideation), worse global health, or more alcohol use during lockdown than optimists?

Significantly fewer optimists reported that they had anxiety (5.1\%) compared with pessimists $(24.7 \%$; $\left.\chi^{2}(1, N=4,527)=293.44, p<.001\right)$ during the COVID-19 lockdown. The same was the case for depression, with $3.4 \%$ of optimists reporting depression compared with $18.4 \%$ of pessimists $\left(\chi^{2}(1, N=4,527)=220.15\right.$, $p<.001)$. Although the most prevalent problem for both optimists and pessimists during the lockdown was insomnia, the rate was significantly lower among optimists compared with pessimists (19.3\% vs. 39.8\%; $\left.\chi^{2}(1, N=4,527)=209.15, p<.001\right)$.

Fewer optimists than pessimists reported having used alcohol daily during the lockdown (11.5\% vs. $\left.14.3 \% ; \chi^{2}(2, N=4,527)=15.52, p<.01\right)$. There was no significant difference between optimists and pessimists regarding suicide attempts during lockdown $\left(0.1 \%\right.$ and $\left.0.2 \% ; \chi^{2}(1, N=4,527)=1.80, p=.259\right)$. However, significantly more pessimists than optimists reported suicidal ideation during lockdown (5.4\% and $\left.0.7 \% ; \chi^{2}(1, N=4,527)=69.87, p=.001\right)$.

Significantly more optimists in the subjective risk group reported having insomnia during lockdown compared with optimists who did not consider themselves at risk $\left(27.6 \%\right.$ vs. $17.0 \% ; \chi^{2}(1, N=1,766)=23.78$, $p<.001)$. Pessimists in the subjective risk group reported significantly more anxiety compared with pessimists who considered themselves not to be at risk $\left(29.5 \%\right.$ vs. $\left.23.1 \% ; \chi^{2}(1, N=2,761)=11.90, p=.001\right)$. The same was the case for depression $(24.0 \%$ vs. $16.4 \%$; $\left.\chi^{2}(1, N=2,761)=19.95, p<.001\right)$ and insomnia $(47.5 \%$ vs. $\left.37.1 \% ; \chi^{2}(1, N=2,761)=24.20, p<.001\right)$, as shown in Table 3.

Optimists reported significantly better global health compared with pessimists - 87.2 (95\% CI [86.7, $88.8])$ and $84.6(95 \%$ CI $[83.9,85.4]) ; t(4525)=-4.83$, $p<.001$. Among optimists, there was no significant difference in global health scores between optimists in the subjective risk group and optimists who did not consider themselves at risk of experiencing complications from COVID-19. In contrast, pessimists in the subjective risk group reported significantly worse global health than pessimists who did not consider themselves at risk of experiencing complications from COVID-19 - 81.4 (95\% CI [79.9, 82.9]) and $85.8(95 \%$ CI $[84.9,86.6])$ respectively; $t(2759)=5.10$, $p<.001$.

\section{DISCUSSION}

The results from the present study show that optimists were generally less worried during the COVID-19 lockdown than pessimists. Pessimists reported more often than optimists being at risk of experiencing complications from COVID-19 without reporting having any of the known risk factors. Furthermore, pessimists reported a higher prevalence than optimists of anxiety, depression, and insomnia, and poorer global health during the lockdown. Our research extends previous work on optimism in light

\section{Table 2}

Belonging in the risk group by self-definition and objective considerations

\begin{tabular}{|c|c|c|c|}
\hline & $\begin{array}{c}\text { Optimists } \\
\%(n)\end{array}$ & $\begin{array}{c}\text { Pessimists } \\
\%(n)\end{array}$ & $p$ \\
\hline Subjective risk group & $19.4(343)$ & $26.0(718)$ & $<.001$ \\
\hline Self-reported listed disease $\mathrm{a}^{\mathrm{a}}$ & $17.7(312)$ & $20.0(553)$ & .021 \\
\hline Self-reported other disease ${ }^{b}$ & $0.5(8)$ & $0.9(25)$ & .106 \\
\hline Over 70 years of age, with no disease & $1.0(18)$ & $0.9(26)$ & .847 \\
\hline Infected by COVID-19 & $1.7(30)$ & $1.3(35)$ & .250 \\
\hline Objective risk group ${ }^{c}$ & $20.7(366)$ & $22.8(631)$ & .021 \\
\hline Reported being at risk, but were not & $9.1(134)$ & $14.3(320)$ & $<.001$ \\
\hline
\end{tabular}


Self-reported mental health during lockdown among optimists and pessimists, and according to reporting being at risk or not of experiencing complications from COVID-19

\begin{tabular}{|c|c|c|c|c|c|c|c|c|c|}
\hline & \multicolumn{3}{|c|}{ Optimists } & \multicolumn{6}{|c|}{ Pessimists } \\
\hline & $\begin{array}{c}\text { All } \\
\text { optimists } \\
N=1766 \\
\%(n)\end{array}$ & $\begin{array}{c}\text { Subjective } \\
\text { risk } \\
\text { group }^{\text {a }} \\
n=369 \\
\%(n)\end{array}$ & $\begin{array}{c}\text { No risk } \\
\text { group }^{\mathrm{b}} \\
n=1397 \\
\%(n)\end{array}$ & $p^{c}$ & $\begin{array}{c}\text { All } \\
\text { pessimists } \\
N=2761 \\
\%(n)\end{array}$ & $\begin{array}{c}\text { Subjective } \\
\text { risk group } \\
\begin{array}{c}n=741 \\
\%(n)\end{array}\end{array}$ & $\begin{array}{l}\text { No risk } \\
\text { group } \\
n=2020 \\
\%(n)\end{array}$ & $p^{c}$ & $p^{\mathrm{d}}$ \\
\hline Anxiety & $5.1(90)$ & $6.1(21)$ & $4.8(69)$ & .339 & $24.7(683)$ & $29.5(212)$ & $23.1(471)$ & .001 & .001 \\
\hline Depression & $3.4(60)$ & $3.1(44)$ & 4.7 (19) & .182 & $18.4(508)$ & $24.0(172)$ & $16.4(336)$ & $<.001$ & .001 \\
\hline Insomnia & $19.3(340)$ & $27.6(102)$ & $17.0(238)$ & $<.001$ & 39.8 (1098) & $47.5(341)$ & $37.1(757)$ & $<.001$ & .001 \\
\hline $\begin{array}{l}\text { Suicidal } \\
\text { ideation }\end{array}$ & $0.7(12)$ & $0.8(3)$ & $0.6(9)$ & .809 & $5.4(149)$ & $7.2(52)$ & $4.7(97)$ & .013 & .001 \\
\hline $\begin{array}{l}\text { Suicidal } \\
\text { attempts }\end{array}$ & $0.1(1)$ & $0.0(1)$ & $0.1(1)$ & .806 & $0.2(6)$ & $0.3(6)$ & $0.2(4)$ & .654 & .259 \\
\hline
\end{tabular}

Note. ${ }^{\text {a }}$ Subjective risk group - self-defined to be at risk of experiencing complications from COVID-19; ${ }^{\mathrm{b}}$ no risk group - participants who did not consider themselves to be at risk of experiencing complications from COVID-19; ${ }^{c} p$ value between the subjective risk group and the no risk group; ${ }^{\mathrm{d}} p$ value between all optimists and pessimists.

of adverse events. We show how optimists and pessimists handle a pandemic emotionally, and that optimists' subjective perception of belonging to the group at risk of experiencing complications from COVID-19 was consistent with a more objective perception.

1. To what degree are optimists and pessimists concerned about the COVID-19 pandemic?

Optimists were generally less worried about the pandemic than pessimists. This was expected since optimists are more likely to expect good things to happen regardless of the situation (Carver et al., 2010), and have an approach to life reflecting the belief that good outcomes require some effort (Carver \& Connor-Smith, 2010). Thus, optimists will employ more problem-solving and cognitive restructuring to cope with the pandemic, and will be more inclined to have hope for the future. In contrast, pessimists expect bad things to happen, which is exemplified by the finding that more pessimists than optimists reported that they might suffer financial loss.

2. Do pessimists report more often than optimists being at risk of experiencing COVID-19 complications without having any known risk factors?

When comparing optimists' and pessimists' selfreported risk, significantly more pessimists reported that they were at risk for COVID-19 complications, although they had none of the risk factors that were listed in the study. In addition to overestimating the risk of becoming infected by COVID-19, pessimists may also expect a more serious clinical outcome. We know that pessimists have negative expectations of the future, believing that they have limited control over outcomes. Thus, the COVID-19 pandemic might well have triggered a fear response among pessimists resulting in a disproportionate risk perception. Alternatively, their response could be viewed as defensive pessimism. Defensive pessimists are people who, in their pursuit of avoiding disappointment over unfulfilled expectations, imagine worst-case outcomes and plan accordingly (Norem \& Chang, 2002).

However, another explanation for why more pessimists than optimists thought they were in the risk group could be that optimists might have a more correct perception regarding being at risk or not. Another interpretation could be that this is an optimistic bias, which refers to the belief that bad things are less likely to befall oneself than others (Sharot, 2011). Optimistic bias may not necessarily be viewed as positive, as it can lead people to underestimate their likelihood of contracting a disease (Sharot, 2011) and therefore ignore public health warnings (Wise et al., 2020).

3. Do pessimists report more mental health problems (anxiety, depression, insomnia, and suicidal ideation), worse global health, or more alcohol use during lockdown than optimists?

The prevalence of anxiety and depression was significantly higher among pessimists compared with optimists. This was expected, since previous research has shown that optimism is associated with less distress in a wide range of groups and contexts; for an overview, see Carver et al. (2010). The anxiety and depression reported during the COVID-19 outbreak may be associated with fear of becoming
Optimists' and pessimists' mental health during the COVID-19 pandemic 
infected and the rapidly increasing number of cases. Fear is one of the central emotional responses during a pandemic (Van Bavel et al., 2020). In addition, anxiety and depression could also be associated with economic-related stress, social distance restrictions, travel restrictions, and changes in daily life. In view of our results, it seems that pessimists - who considered themselves to be at risk of experiencing complications from COVID-19 and reported having financial concerns - are at the greatest risk of experiencing anxiety and depression.

Fewer optimists had suicidal ideation than pessimists during the COVID-19 period, which is consistent with previous findings associating optimism with fewer suicidal thoughts and behaviors (Chang et al., 2013; Huffman et al., 2016; Schou-Bredal et al., 2019). Depression has been found to be associated with suicidal ideation (Rogers et al., 2018). However, it has also been shown that optimism may be associated with lower risk for suicidal ideation, above and beyond the effects of depressive symptoms (Huffman et al., 2016). Pessimists also reported using more alcohol during the lockdown than optimists. This is in agreement with previous research showing that pessimists are more vulnerable than optimists to maladaptive behavior (Carver et al., 2010). However, since we do not know how much alcohol they consumed prior to the lockdown, we cannot claim that the pandemic lockdown resulted in more alcohol consumption.

In the present study, the most prevalent problem during the COVID-19 lockdown was insomnia, for both pessimists and optimists, which accords with studies that have investigated sleep change/insomnia during the COVID-19 outbreak (Gualano et al., 2020; Lin et al., 2020; Pappa et al., 2020; Voitsidis et al., 2020). Lin and colleagues (2020) found that during the COVID-19 outbreak, the prevalence of insomnia increased significantly. Together with findings elsewhere, we found that insomnia is highly prevalent and associated with the COVID-19 outbreak (Voitsidis et al., 2020) and probably related to worries, anxiety, and depression experienced in relation to the pandemic. However, optimists reported a lower prevalence of insomnia. Thus, optimism may be a protective factor.

Overall, optimists reported significantly better global health (including perceived health and quality of life) compared with pessimists during the COVID-19 lockdown. It appears that regardless of the situation, optimists will report better global health than pessimists. In a study of victims of a natural disaster, it was found that compared with optimists, pessimists nurtured little hope for the future and were more at risk for depressive and anxiety disorders, with subsequent impairment of quality of life (van der Velden et al., 2007). The same outcome appears to apply for pessimists during the COVID-19 lockdown.

\section{CLINICAL IMPLICATIONS}

Clinicians should be aware that pessimists appear to be at greater risk of experiencing anxiety, depression, and insomnia during a pandemic lockdown. Furthermore, pessimists considered themselves to be at risk of experiencing complications from COVID-19 more often than optimists, even though they did not belong to the risk group as defined by the health authorities. It may be beneficial for pessimists if they were helped to assess the health risks more realistically. This may also reduce the psychological distress associated with the feeling of being at risk for illness.

\section{STRENGTHS AND LIMITATIONS}

To our knowledge, this is the first study to investigate mental health differences between optimists and pessimists during a pandemic outbreak. As the study was conducted during the outbreak and lockdown of the COVID-19 pandemic in Norway, we could measure the immediate psychological impact of the pandemic on optimists and pessimists.

The study has some limitations. Given the time sensitivity of the COVID-19 outbreak, we used a snowball sampling strategy. Thus, the study's population may not be representative of the general population. There was also oversampling of females, suggesting a selection bias. Furthermore, the sample was dominated by young, urban, and highly educated persons. In addition, the majority of those $(61 \%)$ who responded to the present survey were classified as pessimists, which differs from other studies that have used the same criteria for categorization (Schou-Bredal et al., 2017). It appears that pessimists were more inclined to participate in a survey concerned with worries about COVID-19. A final limitation is that self-reported outcomes rely completely on the respondent as a source of information and are therefore highly subjective in nature.

\section{CONCLUSIONS}

Optimists were generally less worried about the COVID-19 pandemic than pessimists. However, pessimists more often reported being at risk of experiencing complications from COVID-19 without having any of the known risk factors. It appears that being in the risk group for COVID-19 does not affect optimists as much as pessimists. Optimists reported a lower prevalence of anxiety, depression, insomnia, and suicidal ideation than pessimists during the outbreak. Optimists also reported significantly better global health compared with pessimists.

\section{ACKNOWLEDGEMENT}

The authors thank the study participants. 


\section{AVAILABILITY OF DATA AND MATERIALS}

The datasets used and/or analyzed during the current study are available from the corresponding author on reasonable request.

\section{RefERENCES}

Aaronson, N. K., Ahmedzai, S., Bergman, B., Bullinger, M., Cull, A., Duez, N. J., Filiberti, A., Flechtner, H., Fleishman, S. B., \& de Haes, J. C. (1993). The European Organization for Research and Treatment of Cancer QLQ-C30: a quality-of-life instrument for use in international clinical trials in oncology. Journal of the National Cancer Institute, 85, 365-376. https://doi.org/10.1093/jnci/85.5.365

Carver, C. S., \& Connor-Smith, J. (2010). Personality and coping. Annual Review of Psychology, 61, 679-704. https://doi.org/10.1146/annurev. psych.093008.100352

Carver, C. S., \& Scheier, M. F. (2014). Dispositional optimism. Trends in Cognitive Sciences, 18, 293299. https://doi.org/10.1016/j.tics.2014.02.003

Carver, C. S., Scheier, M. F., \& Segerstrom, S. C. (2010). Optimism. Clinical Psychology Review, 30, 879-889. https://doi.org/10.1016/j.cpr.2010.01.006

Cava, M. A., Fay, K. E., Beanlands, H. J., McCay, E. A., \& Wignail, R. (2005). The experience of quarantine for individuals, affected by SARS in Toronto. Public Health Nursing, 22, 398-406. https:// doi.org/10.1111/j.0737-1209.2005.220504.x

Chang, E. C., Yu, E. A., Lee, J. Y., Hirsch, J. K., Kupfermann, Y., \& Kahle, E. R. (2013). An examination of optimism/pessimism and suicide risk in primary care patients: Does belief in a changeable future make a difference? Cognitive Therapy and $R e$ search, 37, 796-804. https://doi.org/10.1007/s10608012-9505-0

Colby, D. A., \& Shifren, K. (2013). Optimism, mental health, and quality of life: a study among breast cancer patients. Psychology, Health \& Medicine, 18 10-20. https://doi.org/10.1080/13548506.2012.686619

Gualano, M. R., Lo Moro, G., Voglino, G., Bert, F., \& Siliquini, R. (2020). Effects of COVID-19 lockdown on mental health and sleep disturbances in Italy. International Journal of Environmental Research and Public Health, 17, 4779. https:// doi.org/10.3390/ijerph17134779

Guillemin, F., Bombardier, C., \& Beaton, D. (1993). Cross-cultural adaptation of health-related quality of life measures: literature review and proposed guidelines. Journal of clinical epidemiology, 46, 14171432. https://doi.org/10.1016/0895-4356(93)90142-n

Hirsch, J. K., Walker, K. L., Chang, E. C., \& Lyness, J. M. (2012). Illness burden and symptoms of anxiety in older adults: Optimism and pessimism as modera- tors. International Psychogeriatrics, 24, 1614-1621. https://doi.org/10.1017/s1041610212000762

Huffman, J. C., Boehm, J. K., Beach, S. R., Beale, E. E., DuBois, C. M., \& Healy, B. C. (2016). Relationship of optimism and suicidal ideation in three groups of patients at varying levels of suicide risk. Journal of Psychiatric Research, 77, 76-84. https:// doi.org/10.1016/j.jpsychires.2016.02.020

Lin, K., Yang, B. X., Luo, D., Liu, Q., Ma, S., Huang, R., Lu, W., Majeed, A., Lee, Y., Lui, L., Mansur, R. B., Nasri, F., Subramaniapillai, M., Rosenblat, J. D., Liu, Z., \& McIntyre, R. S. (2020). The mental health effects of COVID-19 on health care providers in China. American Journal of Psychiatry, 177, 635636. https://doi.org/10.1176/appi.ajp.2020.20040374

Mahase, E. (2020). China coronavirus: WHO declares international emergency as death toll exceeds 200. BMJ, 368, m408. https://doi.org/10.1136/bmj.m408

Norem, J. K., \& Chang, E. C. (2002). The positive psychology of negative thinking. Journal of Clinical Psychology, 58, 993-1001. https://doi.org/10.1002/jclp.10094

Pappa, S., Ntella, V., Giannakas, T., Giannakoulis, V. G., Papoutsi, E., \& Katsaounou, P. (2020). Prevalence of depression, anxiety, and insomnia among healthcare workers during the COVID-19 pandemic: a systematic review and meta-analysis. Brain, Behavior, and Immunity, 88, 901-907. https://doi.org/10.1016/j. bbi.2020.05.026

Rogers, M. L., Stanley, I. H., Hom, M. A., Chiurliza, B., Podlogar, M. C., \& Joiner, T. E. (2018). Conceptual and empirical scrutiny of covarying depression out of suicidal ideation. Assessment, 25, 159-172. https://doi.org/10.1177/1073191116645907

Scheier, M. F., Carver, C. S., \& Bridges, M. W. (1994). Distinguishing optimism from neuroticism (and trait anxiety, self-mastery, and self-esteem): a reevaluation of the Life Orientation Test. Journal of Personality and Social Psychology, 67, 1063-1078. https://doi.org/10.1037//0022-3514.67.6.1063

Schou-Bredal, I., Bonsaksen, T., Heir, T., Skogstad, L., Lerdal, A., Grimholt, T., \& Ekeberg, Ø. (2019). Optimists report fewer physical and mental health conditions than pessimists in the general Norwegian population. Health Psychology Report, 7, 9-18. https://doi.org/10.5114/hpr.2019.81003

Schou-Bredal, I., Heir, T., Skogstad, L., Bonsaksen, T., Lerdal, A., Grimholt, T., \& Ekeberg, Ø. (2017). Population-based norms of the Life Orientation TestRevised (LOT-R). International Journal of Clinical and Health Psychology, 17, 216-224. https:// doi.org/10.1016/j.ijchp.2017.07.005

Schou-Bredal, I., \& Ekeberg, Ø. (2016). The stability of dispositional optimism in relation to receiving or not receiving a cancer diagnosis. Psychology, 7, 806-814. https://doi.org/10.4236/psych.2016.76083

Schou, I., Ekeberg, Ø., Ruland, C. M., Sandvik, L., \& Kåresen, R. (2004). Pessimism as a predictor of emotional morbidity one year following breast can-
Optimists' and pessimists' mental health during the COVID-19 pandemic 
cer surgery. Psycho-Oncology, 13, 309-320. https:// doi.org/10.1002/pon.747

Schou, I., Ekeberg, Ø., Sandvik, L., \& Ruland, C. M. (2005). Stability in optimism-pessimism in relation to bad news: a study of women with breast cancer. Journal of Personality Assessment, 84, 148-154. https://doi.org/10.1207/s15327752jpa8402_04

Sharot, T. (2011). The optimism bias. Current Biology, 21, R941-945. https://doi.org/10.1016/j.cub.2011.10.030

Van Bavel, J. J., Baicker, K., Boggio, P. S., Capraro, V., Cichocka, A., Cikara, M., Crockett, M. J.,

Schou-Bredal, Tine Grimholt, Tore Bonsaksen, Laila Skogstad, Trond Heir, Øivind Ekeberg Crum, A. J., Douglas, K. M., Druckman, J. N., Drury, J., Dube, O., Ellemers, N., Finkel, E. J., Fowler, J. H., Gelfand, M., Han, S., Haslam, S. A., Jetten, J., Kitayama, S., ...Willer, R. (2020). Using social and behavioural science to support COVID-19 pandemic response. Nature Human Behaviour, 4, 460-471. https://doi.org/10.1038/s41562-020-0884-z van der Velden, P. G., Kleber, R. J., Fournier, M., Grievink, L., Drogendijk, A., \& Gersons, B. P. (2007). The association between dispositional optimism and mental health problems among disaster victims and a comparison group: a prospective study. Journal of Affective Disorders, 102, 35-45. https://doi.org/10.1016/j.jad.2006.12.004

Voitsidis, P., Gliatas, I., Bairachtari, V., Papadopoulou, K., Papageorgiou, G., Parlapani, E., Syngelakis, M., Holeva, V., \& Diakogiannis, I. (2020). Insomnia during the COVID-19 pandemic in a Greek population. Psychiatry Research, 289, 113076. https://doi.org/10.1016/j.psychres.2020.113076

Wise, T., Zbozinek, T. D., Michelini, G., Hagan, C. C., \& Mobbs, D. (2020). Changes in risk perception and protective behavior during the first week of the COVID-19 pandemic in the United States. PsyArXiv. https://doi.org/10.31234/osf.io/dz428 